\title{
Research of Gap Filler Material in the GaN Transistor Thermal Management
}

Sun, Bainan; Iversen, Niels Elkjær; Zhang, Zhe; Andersen, Michael A. E.

Published in:

Proceedings of 10th International Conference on Power Electronics

Publication date:

2019

Document Version

Peer reviewed version

Link back to DTU Orbit

Citation (APA):

Sun, B., Iversen, N. E., Zhang, Z., \& Andersen, M. A. E. (2019). Research of Gap Filler Material in the GaN Transistor Thermal Management. In Proceedings of 10th International Conference on Power Electronics [8796905] IEEE.

\section{General rights}

Copyright and moral rights for the publications made accessible in the public portal are retained by the authors and/or other copyright owners and it is a condition of accessing publications that users recognise and abide by the legal requirements associated with these rights.

- Users may download and print one copy of any publication from the public portal for the purpose of private study or research.

- You may not further distribute the material or use it for any profit-making activity or commercial gain

- You may freely distribute the URL identifying the publication in the public portal

If you believe that this document breaches copyright please contact us providing details, and we will remove access to the work immediately and investigate your claim. 


\title{
Research of Gap Filler Material in the GaN Transistor Thermal Management
}

\author{
Bainan Sun, Niels Elkjær Iversen, Zhe Zhang, Michael A.E. Andersen \\ Department of Electrical Engineering \\ Technical University of Denmark \\ 2800 Kongens Lyngby, Denmark
}

\begin{abstract}
High power dissipation in the small package Gallium Nitride (GaN) transistor calls for challenge in thermal design. This paper compares the impact of different gap filler materials in the GaN transistor power dissipation. Simulation and experimental results are given to reveal the maximum power dissipated in each setup, which validates the critical impact of gap filler material in thermal design. The developed test procedure and thermal model are elaborated, which can be easily applied to the estimation of thermal management in other GaN transistor applications.
\end{abstract}

Index Terms-thermal dissipation, GaN transistor, gap filler, thermal model.

\section{INTRODUCTION}

For the benefit of low parasitic impedance and fast switching capability, GaN transistor has gained much attention in recent years. High frequency converter based on the $\mathrm{GaN}$ transistor largely shrinks the volume of passive filters and achieves high power density [1]-[3]. However, switching loss during the high frequency switching and the small footprint of GaN transistor lead to extra challenges in the heat dissipation [4], [5]. Thermal management is critical in the high frequency and high power rate converter design [6]-[8].

The key issue of thermal management in power converter is to reduce the junction to ambient thermal resistance, which aims to protect the power transistor from overheating. Among them, PCB material is one of the widely researched topic. FR4 epoxy is commonly adopted as the base material of conventional $\mathrm{PCB}$, which has a low thermal conductivity around $0.3 \mathrm{~W} / \mathrm{mK}$ [9]. Metal core PCB (MCPCB) is then introduced to include the metal substrate (usually cooper or aluminum) and enhance the thermal conductivity up to 30 $\mathrm{W} / \mathrm{mK}$, which is widely adopted in power LED module [10]. Application of MCPCB is further researched in [11], where thermal conductivity is further increased by thermal microvias (up to $200 \mathrm{~W} / \mathrm{mK}$ with copper core). Direct bonded copper (DBC) is introduced as one further step in circuit board cooling technique. Circuit traces are directly etched on the copper plane and bond wires are adopted to complete the electric conduction. Benefit from the large thermal conductivity of copper material $(401 \mathrm{~W} / \mathrm{mK}), \mathrm{DBC}$ is widely adopted in power module design [2], [12]. By adopting DBC technique, the total thermal resistance (from junction to heatsink) is reduced to $2.4 \mathrm{~K} / \mathrm{W}$ in the $\mathrm{GaN}$ transistor application [13]. Other improvement in heat dissipation can be found in heat sink and forced convection design [4], [14].

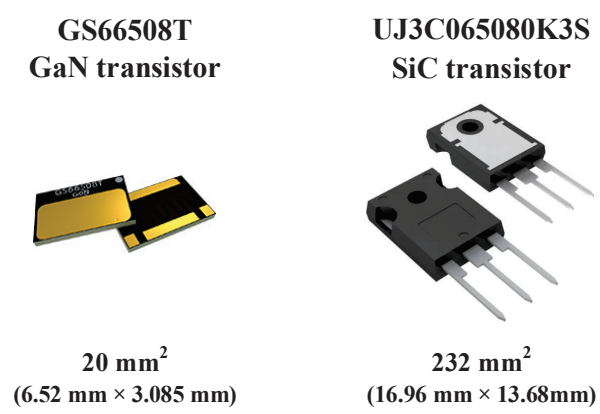

Fig. 1. Thermal pad area comparison.

Beyond the above-mentioned topics, research on the gap filler is rarely mentioned. Gap filler is the electric-isolation component in series connected between the transistor thermal pad and the heat sink. Thermal conductivity of the gap filler material has a direct impact on the transistor junction to ambient thermal resistance. Especially for the GaN transistor, the thermal dissipation capacity is limited and the impact of the gap filler thermal resistance is thus evident. Thermal resistance of the gap filler can be estimated according to (1)

$$
R_{g p}=\frac{1 / k_{g p}}{w_{p a d} \cdot l_{p a d}} \cdot h_{g p}
$$

, where $k_{g p}$ is the thermal conductivity of the gap filler material, $w_{\text {pad }}$ and $l_{\text {pad }}$ are the dimensions of the transistor thermal pad, and $h_{g p}$ is the nominal thickness of the gap filler. Fig. 1 provides an intuitive comparison of the thermal pad dimensions between the GaN transistor GS66508T (650 V, 30 A) and SiC transistor UJ3C065080K3S (650 V, 31 A). Surface mount device (SMD) package adopted by the GaN transistor largely reduces the parasitic inductance and the form factor. On the other hand, the thermal pad space of the GaN transistor shrinks by 11 times compared with the through hole package widely adopted by the Silicon and $\mathrm{SiC}$ transistor. According to (1), even applied with the same gap filler material, the gap filler thermal resistance in $\mathrm{GaN}$ transistor application can be 11 times higher than the $\mathrm{SiC}$ transistor application. This generally omitted topic in the GaN transistor thermal management can be a decisive factor in the power density oriented converter design.

A thorough comparison of different gap filler materials in the $\mathrm{GaN}$ transistor application is given in this paper. Quan- 
titative experimental results reveals the direct impact of gap filler material on the transistor junction temperature. The test configuration and thermal model is introduced in section II. Experimental results are shown in section III and comparison of different gap fillers is given. Section IV concludes the paper.

\section{Illustration OF the GAP Filler Test}

\section{A. Test Configuration}

Configuration of the gap filler test is shown in Fig. 2. E-mode GaN transistor GS66508T (650 V, $30 \mathrm{~A})$ with the laminate SMD package is picked as the device under test. The top-side thermal pad is internally connected to the source pad. Bottom side of the transistor is soldered to the normal FR4 PCB (1.5 mm thickness). Programmable DC source applies a negative voltage bias between the drain pad and the source pad of the transistor through vias, where the reverse conduction loss is generated. This loss is stable and measurable, which is ideal for quantitative research on thermal management. Reverse conduction loss is controlled by the programmable DC source in the constant current (CC) mode, which can be further increased by a negative bias on the transistor gate-source voltage. Negative temperature coefficient (NTC) thermistor with 0402 package is connected to the thermal via to measure the junction temperature. Data from the thermistor connected multimeter is calibrated with measurement results from the thermal camera to guarantee the precision. Top side of the transistor is installed to a sufficiently large heat sink, with the gap filler in between to provide galvanic isolation. Forced air convection is applied to further reduce the thermal resistance of the heat sink.

\section{B. Gap Filler Material Comparison}

Five different gap filler materials are compared in the test. They are three silicone sheet materials and two ceramic-based materials. The material properties are listed in TABLE I. The thermal conductivity of each materials varies from 1.5 $\mathrm{W} / \mathrm{mK}$ to $170 \mathrm{~W} / \mathrm{mK}$. On the other hand, the price of each material shows proportional correlation to the material thermal conductivity, which varies from $0.00025 \mathrm{USD} / \mathrm{mm}^{2}$ to 0.1 USD / $\mathrm{mm}^{2}$ (prizes are estimations for prototype builds).

Based on equation (1), it is then possible to estimate the thermal resistance of each gap filler material for the GaN transistor application. As shown in Fig. 3, gap filler thermal resistance is estimated according to the thermal pad

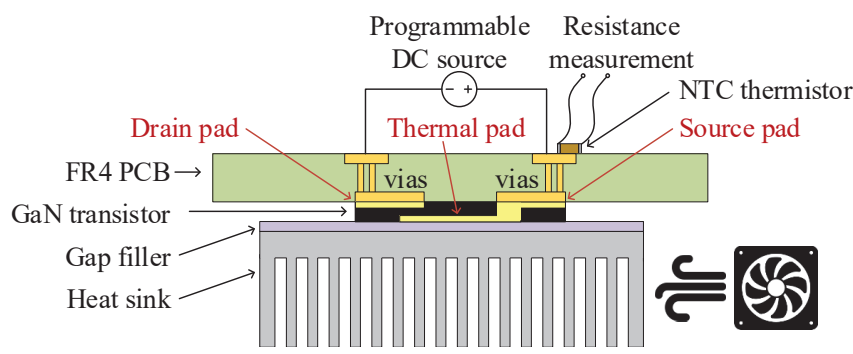

Fig. 2. Gap filler test configuration. dimensions of GS66508T and two typical gap filler thickness. The thermal resistance of the five gap fillers varies from 0.3 $\mathrm{K} / \mathrm{W}$ to $34 \mathrm{~K} / \mathrm{W}$. To provide a general guide for the material thermal conductivity selection, the general reciprocal curve $f(x)=a x^{-1}$ is first discussed. A critical point $(\sqrt{a}, \sqrt{a})$ can be defined in reciprocal curve, where $f(x)$ decreases dramatically to the left of this point and the slope is much lowered to the right of this point. Applying this idea to equation (1), the critical thermal conductivity $k_{c}$ can thus be defined as (2).

$$
k_{c}=\sqrt{\frac{h_{g p}}{w_{p a d} \cdot l_{\text {pad }}}}
$$

The critical thermal conductivity $k_{c}$ is determined by the thermal pad dimensions and the selected gap filler thickness, which varies between different transistor applications. Based on this value, three design rules can be concluded as the guideline for the gap filler material selection:

- Gap filler material with the thermal conductivity lower than the critical value should be avoided.

- For a given gap filler material and thermal pad dimensions, thinner gap filler thickness can provide lower thermal resistance, boundary of which is limited by the material electrical insulation capacity.

- Impact of the gap filler thickness is more evident for the gap filler material with the thermal conductivity lower than the critical value.

For GS66508T, $k_{c}$ is $7.1 \mathrm{~W} / \mathrm{mK}$ for the gap filler with 1 $\mathrm{mm}$ thickness and $5.0 \mathrm{~W} / \mathrm{mK}$ for the gap filler with $0.5 \mathrm{~mm}$ thickness. Between the five gap fillers, thermal conductivity of Toptronic is lower than this critical value. Laird \& $\alpha \mathrm{Gel}$ are around this critical value, while Rubalit \& Alunit are expected to well outperform the rest with their thermal conductivity much higher than the critical value.

\section{Thermal Model}

Thermal model of the test configuration is established based on the Cauer equivalent model, as shown in Fig. 4. The equivalent electrical circuit is formulated to emulate the thermal conduction process between the system element, which can

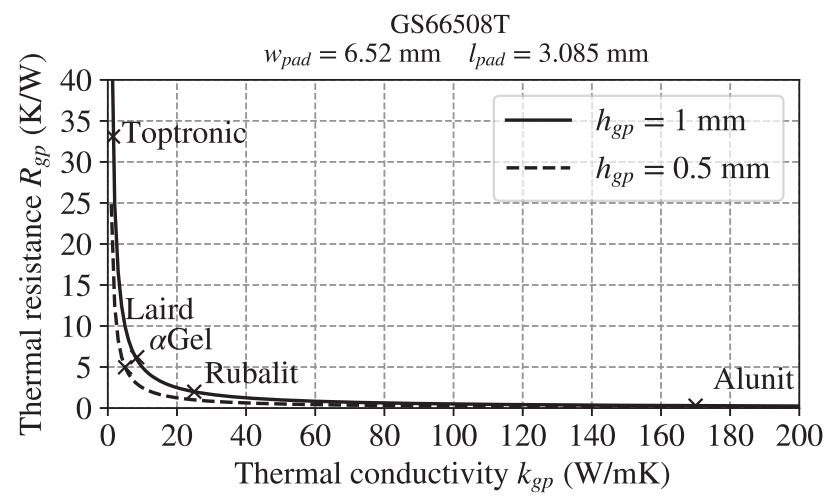

Fig. 3. Gap filler thermal resistance estimated for GS66508T application. 
TABLE I

COMPARISON OF GAP FILlER MATERIAL

\begin{tabular}{c|c|c|c|c|c}
\hline \hline & Brand name & Material & $\begin{array}{c}\text { Thermal conductivity } \\
(\mathrm{W} / \mathrm{mK})\end{array}$ & $\begin{array}{c}\text { Nominal thickness } \\
(\mathrm{mm})\end{array}$ & $\begin{array}{c}\text { Price } \\
\left(\mathrm{USD} / \mathrm{mm}^{2}\right)\end{array}$ \\
\hline 1 & Laird & Silicone sheet & 5 & 0.5 & $\sim 0.0013$ \\
\hline 2 & $\alpha$ Gel & Silicone sheet & 8 & 1 & $\sim 0.0027$ \\
\hline 3 & Toptronic & Silicone sheet & 1.5 & 1 & $\sim 0.00025$ \\
\hline 4 & Rubalit & $\mathrm{Al}_{2} \mathrm{O}_{3}$ (Ceramic base) & 25 & 1 & $\sim 0.003$ \\
\hline 5 & Alunit & $\mathrm{AlN}$ (Ceramic base) & 170 & 1 & $\sim 0.1$ \\
\hline \hline
\end{tabular}

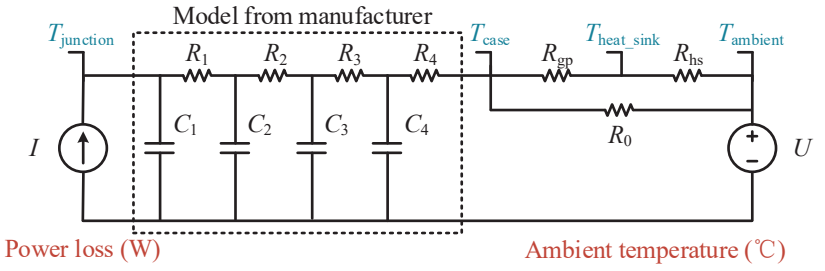

Fig. 4. Thermal model of the gap filler test.

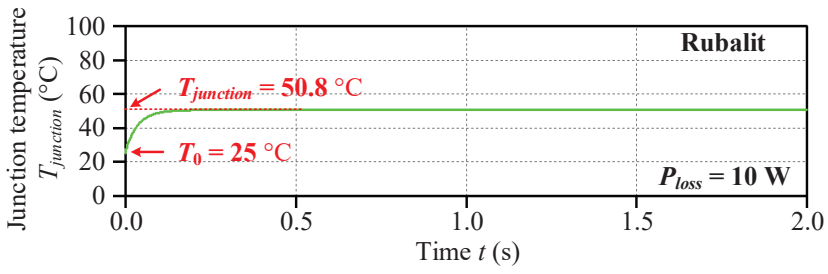

Fig. 5. Simulation waveform of the thermal model in LTSpice.

be easily applied in the SPICE simulation [15]. Power loss from the transistor is analogized to the constant current source. Ambient temperature is analogized to the constant voltage source. Thermal model of the transistor is analogized to the $R C$ network obtained from the manufacturer. $R_{g p}$ and $R_{h s}$ are the thermal resistance of the gap filler and the heat sink respectively. $R_{h s}$ is measured to be $0.5 \mathrm{~K} / \mathrm{W}$ according to the quantitative experiment, which is low to guarantee the accuracy of the $R_{g p}$ measurement. $R_{0}$ analogize the thermal resistance of the heat transfer through the FR4 PCB, which can enhance the simulation accuracy in the high $R_{g p}$ scenario. $R_{0}$ is chosen as $20 \mathrm{~K} / \mathrm{W}$ based on an empirical fitting. $R_{g p}$ can thus be solved within the thermal resistance network according to the measured junction temperature $T_{\text {junction }}$ and the ambient temperature $T_{\text {ambient }}$.

Simulation of the thermal model is carried out in LTSpice. Fig. 5 shows the junction temperature waveform. The rise of transistor junction temperature $T_{\text {junction }}$ follows the $R C$ charging process, while the thermal capacitance of the gap filler and the heat sink is not included. Comparison of the gap filler is done in the constant transistor power loss condition. The room temperature $T_{0}$ is set to be $25^{\circ} \mathrm{C}$ and the transistor junction temperature is compared to evaluate different gap

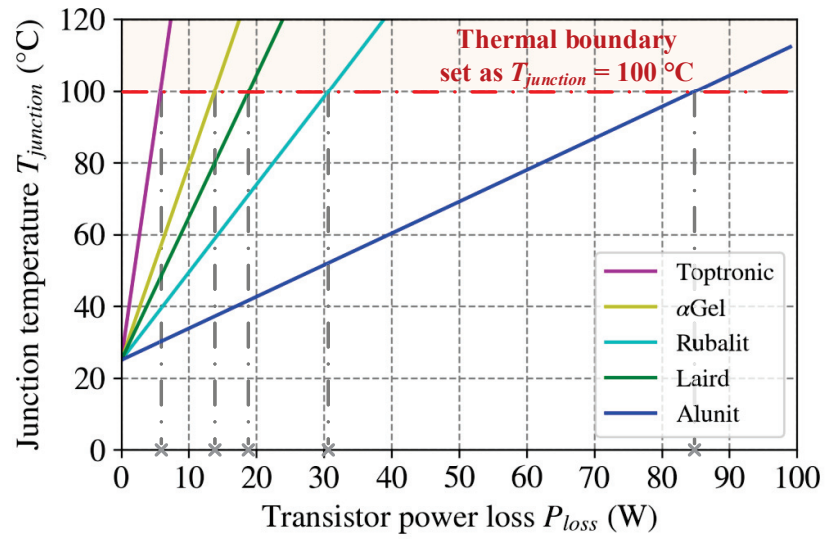

Fig. 6. Estimated junction temperature from the thermal simulation.

filler materials. Fig. 6 plots the estimated junction temperature at different transistor power loss. The thermal boundary is set as $T_{\text {junction }}=100{ }^{\circ} \mathrm{C}$ to justify the maximum power loss allowed for the transistor reliable switching operation. By applying five different gap fillers, the maximum power loss allowed for GS66508T varies from $6 \mathrm{~W}$ to $85 \mathrm{~W}$. This considerate difference validates the significant impact of the gap filler material on the GaN transistor thermal management.

\section{EXPERIMENTAL RESULTS}

\section{A. Test Setup}

Experimental setup is shown in Fig. 7. T $T_{\text {junction }}$ and $T_{\text {ambient }}$ are measured by the NTC thermistor connected to the digital multimeter. NTC thermistor for $T_{\text {junction }}$ measurement is soldered to the source pad via, where a copper connection path can be found to obtain the junction temperature of the transistor accurately. Another two multimeters measure the drain-source current and voltage respectively for power loss calculation. Three DC power supplies are used respectively to apply source-drain voltage, reverse gate bias and power the cooling fan. All the programmable source and multimeters are remote controlled by the laptop running MATLAB script.

To guarantee the test precision, the measured data and the power supply control signal are processed in the MATLAB script, which is written based on Virtual Instrument Software Architecture (VISA) from NATIONAL INSTRUMENTS (NI). 
TABLE II

COMPARISON OF Simulation AND EXPERIMENTAL RESUlTS

\begin{tabular}{|c|c|c|c|c|c|c|}
\hline & Gap material & Malleability of the material & $\begin{array}{l}\text { Estimated thermal } \\
\text { resistance of the gap filler } \\
(\mathrm{K} / \mathrm{W})\end{array}$ & $\begin{array}{c}P_{\text {loss }} \text { simulation } \\
\text { ideal heat sink } \\
\text { (W) }\end{array}$ & $\begin{array}{l}P_{\text {loss }} \text { simulation } \\
\text { actual heat sink } \\
\text { (W) }\end{array}$ & $\begin{array}{c}P_{\text {loss }} \\
\text { experimental results } \\
(\mathrm{W})\end{array}$ \\
\hline 1 & Free air & NA & NA & NA & NA & 3 \\
\hline 2 & Toptronic & Silicone like & 34 & 6 & 6 & 9 \\
\hline 3 & $\alpha \mathrm{Gel}$ & Clay like & 6.4 & 15 & 14 & 19 \\
\hline 4 & Rubalit & Rigid & 2.1 & 35 & 31 & 28 \\
\hline 5 & Laird & Clay like & 3.2 & 18 & 17 & 29 \\
\hline 6 & Alunit & Rigid & 0.3 & 120 & 85 & 35 \\
\hline 7 & Alunit (DBC) & Rigid & 0.3 & 120 & 85 & 78 \\
\hline
\end{tabular}

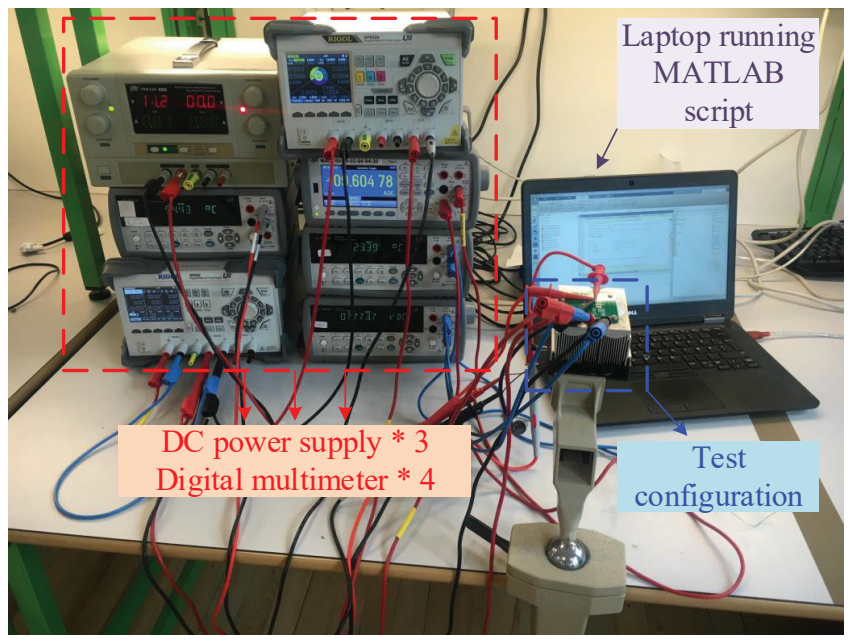

Fig. 7. Experimental setup of the gap filler test.

The test script is explained as the flow chart shown in Fig. 8. The test goal is to obtain the maximum allowed power loss that can maintain the transistor junction temperature lower than $100{ }^{\circ} \mathrm{C}$ for at least 30 minutes. Gap filler test starts from the maximum power from the DC power supply applied on the transistor, which heats up the transistor fast. The boundary temperature is reached immediately and the applied power is switched off. The left-hand side cycle of the test flow chart reduces the applied power step by step at the end of each cycle, until the measured $T_{\text {junction }}$ is lowered beneath $100{ }^{\circ} \mathrm{C}$ at the first measurement point. The right-hand side cycle then measures the $T_{\text {junction }}$ periodically and jump back to the lefthand side cycle once the thermal boundary is reached. The test is ended once the right-hand side cycle is repeated for more than 30 minutes.

\section{B. Experimental Results}

The gap filler test was performed on the different materials to find the maximum continuous power dissipation allowed in the $\mathrm{GaN}$ transistor. To ensure a relatively good thermal connection to the rigid gap fillers, i.e. Rubalit and Alunit, a

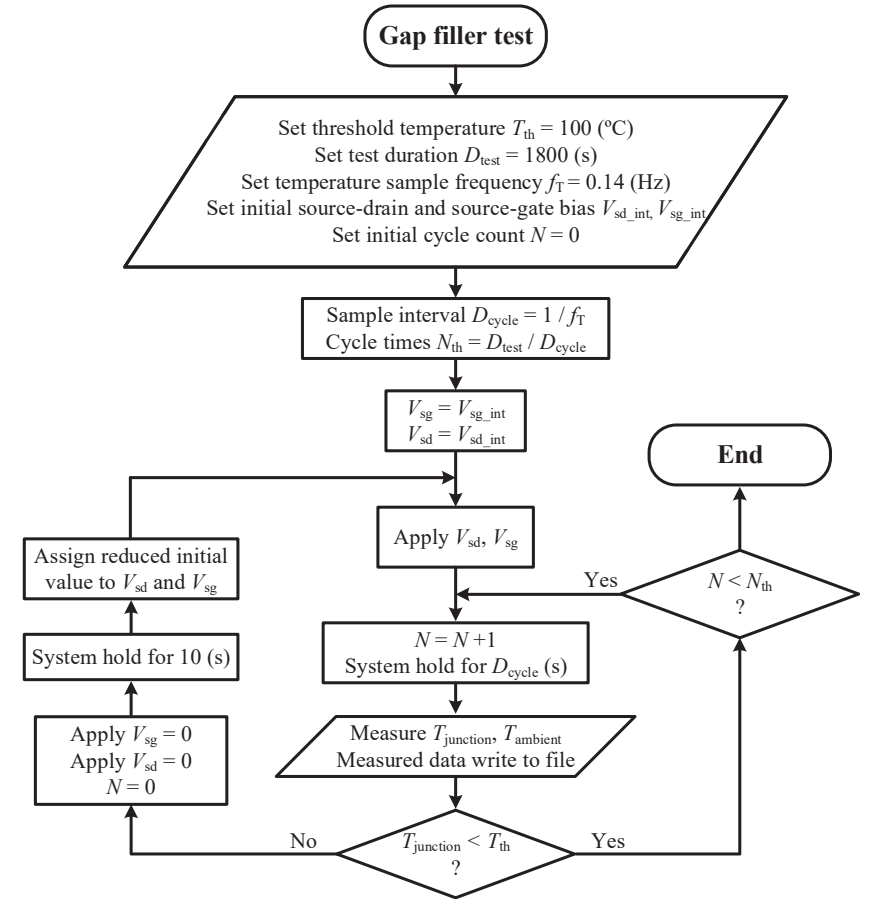

Fig. 8. Flow chart of the gap filler test.

thin layer of thermal paste was applied. In addition to that, an experiment where the Alunit was directly soldered to the thermal pad using a DBC solution was evaluated. Moreover, experimental result of the power dissipation without heat sink in free air condition is shown as comparison.

The experimentally obtained data is shown in Fig. 9. Over $90 \mathrm{~W}$ power loss is applied at the beginning of the test and gradually reduced as the measured $T_{\text {junction }}$ constantly reaches the thermal boundary. $P_{\text {loss }}$ is finalized as the junction temperature is maintained lower than $100{ }^{\circ} \mathrm{C}$ for $30 \mathrm{~min}$ utes. The experimental test results of different gap fillers are summarized in TABLE II, along with expectations evaluated through simulations. For the majority of materials, there exist a good correlation between measurements and simulations. 

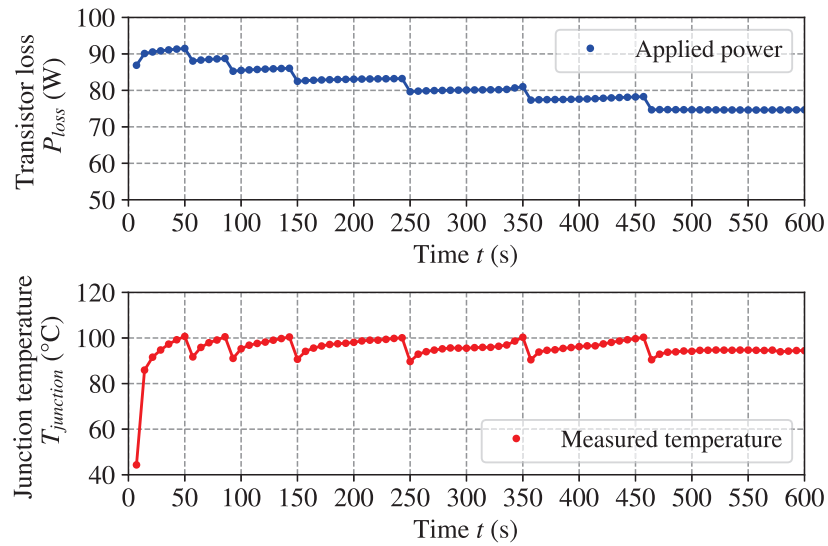

Fig. 9. Measured data from the gap filler test.

However, for the clay like materials, the measured result overperforms $30 \%$ to $70 \%$ compared to the simulations result. This is due to a high level of deformability of these materials. Assuming $30 \%$ to $50 \%$ compression of these materials simulations fit measured results. However, huge material compression should be avoided as it may ruin isolation properties.

The ceramic material Alunit is by far the gap filler material that achieves the best performance. Especially in conjunction with a DBC solution as shown in Fig. 10, where the material is soldered directly to the thermal pad of the $\mathrm{GaN}$ transistor. In this configuration, a power dissipation of $78 \mathrm{~W}$ in the $\mathrm{GaN}$ transistor was measured. For such high power dissipation, the quality of the heat sink is beginning to become a limiting factor. This is also illustrated in TABLE II. For materials with high thermal resistance there is little to no difference between simulations applying an ideal- or the actual-heat sink. However, for materials with low thermal resistance, significantly more power can be dissipated in an ideal heat sink. For the Alunit material, $120 \mathrm{~W}$ is the expected maximum in an ideal heat sink that can be closely achieved with water cooling systems [16]. Even though the Alunit material is by far the most expensive material according to TABLE I, the needed size of the material in a DBC solution is only the size of the thermal pad. With a pad size of approximately $20 \mathrm{~mm}^{2}$, this yields a price of 2 USD per device. This may sound expensive but compared with the price of the $\mathrm{GaN}$ transistor itself, which is approximately $20 \mathrm{USD}$, it is actually not a huge extra cost considering the improved performance.

\section{CONCLUSION}

This paper has described the challenge of dissipating power in small power transistor footprints such as $\mathrm{GaN}$ transistors. These include a low thermal resistance from power transistor to heat sink along with electrical isolation to avoid unwanted power nets on the heat sink. This can be achieved with gap fillers but the allowed power dissipation in the power transistor is strongly dependent on the thermal capabilities of the gap filler material. To investigate the performance of difference

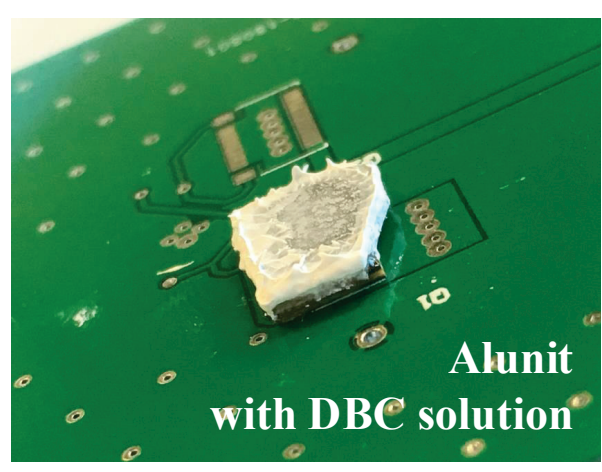

Fig. 10. Alunit gap filler soldered to the transistor thermal pad.

gap filler materials a gap filler test was developed to evaluate the safely allowed power dissipation in a $\mathrm{GaN}$ transistor. Five different materials were investigated and a general selection guide of the gap filler material with different thermal conductivity is given. The measured results correlated well with simulated expectations and it was found that the ceramic-based material Alunit offers great thermal performance. Using this material with a DBC solution where the material is soldered directly on the thermal pad of the GaN transistor, the safely allowed power dissipation was evaluated to be $78 \mathrm{~W}$, which is limited by the thermal resistance of the heat sink. With a nearly ideal heat sink, up to $120 \mathrm{~W}$ can theoretically be dissipated for the chosen power transistor. This amount of allowed power dissipation enables high power converters in the range of multiple kilowatts with $95 \%$ to $99 \%$ efficiency, while using small footprint $\mathrm{GaN}$ transistors. Finally, the presented simulation model and the developed gap filler test can easily be adjusted for various gap fillers and components with a different form factor and properties so that the safely allowed power dissipation can be similarly estimated.

\section{REFERENCES}

[1] A. Kulkarni, A. Gupta, and S. K. Mazumder, "Resolving Practical Design Issues in a Single-Phase Grid-Connected GaN-FET Based Differential-Mode Inverter," IEEE Transactions on Power Electronics, vol. 33, no. 5, pp. 3734-3751, 2017.

[2] A. B. Jorgensen, S. Beczkowski, C. Uhrenfeldt, N. H. Petersen, S. Jorgensen, and S. Munk-Nielsen, "A Fast-Switching Integrated Full-Bridge Power Module Based on GaN eHEMT Devices," IEEE Transactions on Power Electronics, vol. 1, no. c, 2018.

[3] G. Zulauf, S. Park, W. Liang, K. N. Surakitbovorn, and J. Rivas-Davila, "COSS Losses in $600 \mathrm{v}$ GaN Power Semiconductors in Soft-Switched, High- and Very-High-Frequency Power Converters," IEEE Transactions on Power Electronics, vol. 33, no. 12, pp. 10748-10763, 2018.

[4] H. Li, X. Zhang, Z. Zhang, C. Yao, F. Qi, B. Hu, J. Wang, and L. Liu, "Design of a $10 \mathrm{~kW} \mathrm{GaN-based} \mathrm{high} \mathrm{power} \mathrm{density} \mathrm{three-}$ phase inverter," ECCE 2016 - IEEE Energy Conversion Congress and Exposition, Proceedings, 2016.

[5] S.-p. Inverter, C. Zhao, S. Member, B. Trento, L. Jiang, S. Member, E. A. Jones, S. Member, B. Liu, S. Member, Z. Zhang, D. Costinett, F. F. Wang, L. M. Tolbert, J. F. Jansen, R. Kress, and R. Langley, "Design and Implementation of a GaN-Based ,", vol. 4, no. 3, pp. 824-840, 2016.

[6] H. Li, X. Li, Z. Zhang, C. Yao, and J. Wang, "Design consideration of high power GaN inverter," WiPDA 2016 - 4th IEEE Workshop on Wide Bandgap Power Devices and Applications, pp. 23-29, 2016.

[7] E. Gurpinar and A. Castellazzi, "Tradeoff Study of Heat Sink and Output Filter Volume in a GaN HEMT Based Single-Phase Inverter," IEEE 
Transactions on Power Electronics, vol. 33, no. 6, pp. 5226-5239, jun 2018.

[8] E. A. Jones, P. Williford, Z. Yang, J. Chen, F. Wang, S. Bala, J. Xu, and J. Puukko, "Maximizing the voltage and current capability of GaN FETs in a hard-switching converter," Proceedings of the International Conference on Power Electronics and Drive Systems, vol. 2017-Decem, no. December, pp. 740-747, 2018.

[9] K. Wang, L. Wang, X. Yang, X. Zeng, W. Chen, and H. Li, “A Multiloop Method for Minimization of Parasitic Inductance in GaN-Based HighFrequency DC-DC Converter," IEEE Transactions on Power Electronics, vol. 32, no. 6, pp. 4728-4740, 2017.

[10] S. Zhang, W. Xu, Y. Wang, and W. Wang, "Thermal impedance measurements of layered Metal Core PCB used in LED lighting," in 2014 15th International Conference on Electronic Packaging Technology. IEEE, may 2014, pp. 1419-1422.

[11] E. Juntunen, O. Tapaninen, A. Sitomaniemi, M. Jamsa, V. Heikkinen, M. Karppinen, and P. Karioja, "Copper-core MCPCB with therma vias for high-power COB LED modules," IEEE Transactions on Power Electronics, vol. 29, no. 3, pp. 1410-1417, 2014.

[12] J. Reichl, J. S. Lai, A. Hefner, J. M. Ortiz-Rodriguez, and T. Duong, "Design Optimization of Hybrid-Switch Soft-Switching Inverters Using Multiscale Electrothermal Simulation," IEEE Transactions on Power Electronics, vol. 32, no. 1, pp. 503-514, 2017.

[13] C. Yu, C. Buttay, and E. Laboure, "Thermal management and electromagnetic analysis for GaN devices packaging on DBC substrate," IEEE Transactions on Power Electronics, vol. 32, no. 2, pp. 906-910, 2017.

[14] J. Acuna and I. Kallfass, "Substrate Choice and Thermal Optimization of a Half-bridge Power Module based on Chip Scale GaN HEMTs," 2017 19th European Conference on Power Electronics and Applications, EPE 2017 ECCE Europe, vol. 2017-Janua, pp. 1-10, 2017.

[15] K. Górecki and J. Zarebski, "Nonlinear compact thermal model of power semiconductor devices," IEEE Transactions on Components and Packaging Technologies, vol. 33, no. 3, pp. 643-647, 2010.

[16] A. T. Corporation, "Hi-contacttm 4-pass cold plate," data sheet, Sep. 2018 . 